\title{
Pensamento e ação: a sociologia política brasileira em perspectivas
}

BOTELHO, André. O retorno da sociedade: política e interpretações do Brasil. Petrópolis: Vozes, 2019. 297p.

\section{Leonardo Octavio Belinelli de Brito*}

\section{Resumo}

Trata-se da resenha de O retorno da sociedade (Petrópolis, Vozes, 2019), de André Botelho. O livro reúne dez artigos, alguns dos quais em coautoria, em que o autor procura interpretar obras clássicas do pensamento social brasileiro à luz da sociologia política, estabelecendo, com isso, diálogos com pesquisas contemporâneas nacionais e internacionais, ao mesmo tempo em que oferece um "programa forte" para a área. Analisa-se como tais propósitos aparecem no livro.

Palavras-chave: pensamento social brasileiro, sociologia política, interpretações do Brasil, André Botelho.

* Universidade de São Paulo, São Paulo, SP, Brasil. Bolsista de pós-doutorado com financiamento do CNPq. 


\section{Thought and action: sequences of Brazilian political sociology in perspectives}

\section{Abstract}

This is a review of André Botelho's O retorno da sociedade (Petrópolis, Vozes, 2019). The book brings together ten articles, some of which co-authored, in which the author seeks to interpret classical works of Brazilian social thought in the light of political sociology, thereby establishing dialogues with contemporary national and international research, while also offering a "strong program" for the area. Here I analyze how such purposes appear in the book.

Keywords: Brazilian social thinking, political sociology, interpretations of Brazil, André Botelho.

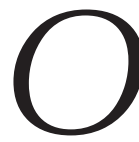

retorno da sociedade: política e interpretações do Brasil, de André Botelho, é um livro denso. Em primeiro lugar, porque reúne dez textos, alguns dos quais em coautoria, reveladores da trajetória de pesquisa do autor na área do pensamento social brasileiro, da qual é um dos principais pesquisadores em atividade. Por isso, coligidos, os artigos adquirem uma notável conexão entre si, iluminando uns aos outros, o que se deve - e eis a segunda e decisiva razão de sua densidade - ao programa teórico-metodológico que os anima. Essa coerência faz com que o conjunto forme, sem dúvida, uma das principais contribuições recentes ao campo de estudos em que se situa.

O livro é dividido em três partes - "O baralhamento entre público e privado", "A política na sociedade: fios contemporâneos" e "Interpretar interpretações do Brasil" - articuladas a partir da proposta de retomada de uma certa tradição da sociologia política brasileira que, ao tematizar a 
problemática relação entre o público e o privado, coloca sua lupa sobre os vínculos que atam Estado e sociedade no Brasil. Nada mais natural, portanto, que a coletânea seja aberta com o artigo "Sequências de uma sociologia política", originalmente publicado na revista Dados, em 2007. Nele, o autor examina as possíveis conexões intelectuais entre as formulações de autores tão diversos no tempo e no espaço como Francisco José de Oliveira Vianna, Victor Nunes Leal, Maria Isaura Pereira de Queiroz e Maria Sylvia de Carvalho Franco.

O artigo extrapola o exame erudito das contribuições desses autores. Como observa Maurício Hoelz, em posfácio ao livro, a proposta metodológica de Botelho, sintetizada na ideia de sequências - esclarecida no posfácio por meio de uma contraposição produtiva com as categorias de "formação", classicamente identificada com as obras de Antonio Candido (Candido, 2014) e Celso Furtado (Furtado, 2007), ${ }^{1}$ e "linhagens", forjada no trabalho de Gildo Marçal Brandão (Brandão, 2007) -, procura atinar para a seriação das ideias sem aderir a argumentos e perspectivas teleológicas, normativas e/ou baseadas na cisão rotineira entre explicações "textualistas" e "contextualistas". Em boa medida, isso se deve ao fato de a categoria permitir a valorização dos elementos contingentes, embora não aleatórios, envolvidos na produção, circulação e recepção das ideias.

O reexame de obras clássicas à luz desse prisma possibilita a Botelho desenvolver uma das teses que perpassam o livro: a de que só é possível compreender a dinâmica política em seu liame com a sociedade. Ou, em outras palavras, trata-se de indicar que o âmbito institucional não possui a autonomia social, e, portanto, epistêmica, suposta em parcela considerável das chamadas "teorias empíricas" da política. Desse ângulo, revela-se que a escolha pelo resgate dessa tradição da sociologia política não possui nada de casual; ao contrário, embora distintos entre si, os autores elencados poderiam ser aproximados às linhagens intelectuais que Brandão (2007) denominou como "idealista orgânica" e "radical de classe média", cuja orientação

"Sobre as implicações teóricas e políticas envolvidas na categoria "formação", ver Arantes (1997); Schwarz (1999). 
cognitiva elementar é a percepção de que os arranjos institucionais devem pressupor um exame das especificidades da forma social sobre a qual se assentarão. Não é à toa que Oliveira Vianna ocupe lugar destacado em O retorno da sociedade, como se verá. O jurista saquarema criticava os liberais por acreditarem que um desenho institucional virtuoso poderia ser capaz de ensejar uma sociedade à sua imagem e semelhança.

Nesse sentido, o livro de Botelho põe em prática uma ideia muito teorizada, mas nem sempre exercitada: a utilização dos clássicos brasileiros como ferramenta para interpelar nossas ciências sociais institucionalizadas e, como não poderia deixar de ser, a realidade social sobre a qual se debruçam. Ou seja, a partir do feixe da sociologia política, são tratados temas relacionados aos fazeres científicos e políticos, para usarmos a conhecida formulação de Max Weber (s/d). Esse programa é levado adiante nos capítulos seguintes da primeira parte, composto por "Passagens para o Estado-nação", originalmente publicado na revista Lua Nova, em 2009, "A sociedade em movimento", publicado em Sociedade e Estado, em 2011, e "Dominação pessoal, vida social e política", surgido pela primeira vez na revista Lua Nova, em 2013, com o título "Teoria e história na sociologia brasileira: a crítica de Maria Sylvia de Carvalho Franco". Os artigos discutem, respectivamente, as formas de pensar e as pesquisas empíricas de Luiz Aguiar da Costa Pinto, Maria Isaura Pereira de Queiroz e Maria Sylvia de Carvalho Franco.

A proposta metodológica é aprofundada na segunda parte, em que é exercitada a partir do diálogo com a sociologia internacional. Sua abertura ocorre com "Sociologia política: relações Estado-sociedade", dedicado à reflexão sobre as especificidades da subdisciplina em contextos internacional, nacional e em relação à ciência política. Seguindo a trilha argumentativa de Reinhard Bendix, Botelho argumenta que o problema teórico e empírico "mais característico" da sociologia política é o da relação entre Estado e sociedade. Desse prisma, o autor estabelece um diálogo crítico com a perspectiva neoinstitucionalista da sociologia política, exemplarmente representada por Theda Skocpol (1985), autora de contribuições influentes 
na recolocação de ênfases na autonomia do plano estatal-institucional. É desse prisma relacional que são vinculadas e historicizadas as diversas agendas contemporâneas da sociologia política, como, por exemplo, a crise do Estado-nação, a formação da cidadania moderna, o surgimento e a dinâmica dos movimentos sociais, além do tema da esfera pública e da sociedade civil.

O diálogo entre a sociologia política internacional historicamente orientada - representada por Bendix, Barrington Moore Jr. e Charles Tilly - e a tradição da sociologia política brasileira, identificada com Florestan Fernandes e Maria Sylvia de Carvalho Franco, é feito no capítulo 6, escrito em coautoria com Antonio Brasil Jr. O nexo que permite a aproximação entre as duas perspectivas é o clássico problema da modernização brasileira, processo que colocaria em relevo a singularidade de diversos aspectos da sociedade local, entre os quais a formação incompleta da cidadania ${ }^{2}$, consequentes das características próprias do passado brasileiro, de origem colonial e rural, conforme tematizadopelos "intérpretes do Brasil". O texto procura compreender a participação social, entendida à maneira de Tilly, do "homem comum".

Não é acidental, portanto, que o pensamento de Oliveira Vianna seja o assunto do capítulo seguinte. Se, claro, há uma indagação sobre o seu sentido, existe igual ênfase na ideia de que ali se configura um repositório de questões, interpretações e hipóteses que ajudam a iluminar os caminhos percorridos por uma ciência social voltada para o contemporâneo. A valorização de Vianna como uma espécie de "patrono" da sociologia política brasileira pode ser entendida como forma de continuação do processo de revalorização intelectual desse autor, iniciado nos anos 1980 e levado adiante por meio da procura por ressonâncias em obras de outros autores, o que efetiva o programa teórico-metodológico calcado na recusa de uma normatividade prévia ao exame direto, corpo a corpo, das formulações

${ }^{2}$ Sobre o tema, Botelho organizou, em parceria com Lilia Schwarcz, o livro Cidadania, um projeto em construção (São Paulo, ClaroEnigma, 2012). 
intelectuais. ${ }^{3}$ Nessa retomada está embutida a ideia de que os achados de Vianna remetem para além da esfera singular de seu pensamento e de sua ação.

A terceira parte do livro é aberta com "Passado e futuro das interpretações do Brasil", publicado originalmente na revista Tempo Social, em 2010. Nele, Botelho procura resgatar a força cognitiva e ideológica do ensaísmo brasileiro dos anos 1920-1940, à luz da sua diversidade interna, aspecto soterrado por imagens que acentuam sua unidade em detrimento de sua diferença, como as produzidas, com sentidos contrários, por Florestan Fernandes e Alberto Guerreiro Ramos. O vínculo com o contemporâneo se estabelece pela discussão pós-positivista do fazer científico, que serve como chave desestabilizadora dos discursos assentados sobre a dimensão pré-científica ou ideológica da imaginação política contida nos ensaios. Ou, por outra, a discussão epistemológica contemporânea permite a Botelho relativizar, de maneira produtiva, a distância estabelecida entre o passado - o ensaísmo - e o presente - as ciências sociais. Por essa razão, pode-se dizer que o texto, ao repor temas, argumentos e questões que tensionam em favor de uma noção mais complexa de objetividade, a oposição tão estrita como costumeira entre "ciência" e "ideologia", também recoloca a relação entre "ciência" e "política".

Nesse resgate, um dos temas-chave é a relação entre ideias, ciência e política. Por essa razão, a revalorização do estudo das ideias como fonte de saber e como fator político reaparece na discussão que Botelho, em parceria com Elide Rugai Bastos, faz da obra de Sérgio Miceli, o mais eminente representante da tradição bourdieusiana na sociologia dos intelectuais brasileiros e latino-americanos. Coerente com a orientação sustentada pelos artigos anteriores, Intelectuais e classes dirigentes no Brasil (1920-45) (Miceli, 2001), originalmente a tese de doutorado de Miceli, é entendida a partir da história - no caso, da própria conformação 3Um marco dessa revalorização foi a publicação da coletânea O pensamento de Oliveira
Vianna, organizada por Elide Rugai Bastos e João Quartim de Moraes (Bastos; Moraes, 1993)
como resultado de um seminário sobre o autor de Populações meridionais do Brasil (1920). 
da sociologia brasileira. Sua perspectiva teria se configurado como uma resposta de matriz microssociológica a um contexto no qual vicejavam interpretações macrossociológicas, das quais a interpretação materialista seria a principal representante.

A obra de Miceli é central para a discussão proposta por Botelho porque aborda, de uma perspectiva própria, a relação entre intelectuais e política no Brasil, par diretamente vinculado a outros, como sociedade e Estado e privado e público. Em seu trabalho, Miceli sugere que os intelectuais brasileiros, em geral, não teriam conquistado a "autonomia" de seu campo, dependendo antes de outros aspectos, entre os quais o mecenato, para exercerem seus papéis sociais. Ou seja, no Brasil, a modernização não teria gerado a autonomização de esferas de valores, como destacaram Max Weber e Pierre Bourdieu, mas teria corrido em paralelo ao processo de cooptação de intelectuais pelas elites políticas, como sugerido por autores como Sérgio Buarque de Holanda (2009) e Raymundo Faoro (2008). Nesse caso, a política teria uma predominância sobre as ideias, formuladas em conformidade com determinações que lhes seriam alheias.

Por essa razão, o ponto que interessa destacar é o lugar das "ideias" no debate proposto por Botelho e Bastos sobre a perspectiva de Miceli, para quem o estudo daquelas acabaria por dificultar a identificação das estruturas sociais que permitiram aos seus formuladores transitarem pelos campos em que se situam. Em última instância, o estudioso das ideias ficaria preso ao autorretrato que seus formuladores fazem de si mesmos. Sem deixar de reconhecer a pertinência das observações de Miceli a respeito do caráter interessado dos textos, Botelho e Bastos observam que "não é preciso concordar com a premissa da autonomia do texto para reconhecer que as ideias possuem um fundamento que ultrapassa a experiência ou mesmo o domínio conceitual do indivíduo" (Botelho; Bastos, 2019, p. 245). Assim, se as ideias são, por excelência, o produto típico dos intelectuais - sendo, portanto, as formas pelas quais esses se situam no mundo -, elas também possuem, como os capítulos anteriores já registram, efeitos e potencialidades que ultrapassam suas condições imediatas, apesar de serem dependentes 
de contextos determinados. "Nosso ponto, em todo caso, é que as ideias não operam apenas no sentido cognitivo, mas também no normativo, e são passíveis de tradução em ações pelos indivíduos e grupos na luta política [...] mesmo para além do seu contexto original" (Botelho; Bastos, 2019, p. 246). O argumento valoriza o contingente e recoloca, ao mesmo tempo e por via diversa, a relação entre ciência e política, frequentemente mediada por ideias.

Sem deixar de lado as singularidades que caracterizam a perspectiva de Botelho, cabe registrar que esse texto, lido em conjunto com os demais, permite ao leitor identificar sua filiação aos trabalhos de Elide Rugai Bastos, socióloga com atuação marcante no processo de institucionalização da área de pensamento social brasileiro a partir de trabalhos de referência sobre autores como Gilberto Freyre, Florestan Fernandes e Oliveira Vianna. Como assinalou Antônio Brasil Jr. (2015), entre os fatos que particularizam a contribuição de Bastos ao campo de estudos está o desenvolvimento de uma metodologia que confere importância ao lugar que as ideias possuem no processo de (re)produção da sociedade. ${ }^{4}$ Essa orientação encontra no livro de Botelho uma nítida sequência.

Sinal disso é o seu desdobramento, em dimensão propositiva, no texto que encerra o livro, no qual é realizado um balanço sobre a produção mais recente na área de pensamento social brasileiro que procura unir dados quantitativos, recolhidos a partir de ferramentas entre as quais se destacam as vinculadas ao projeto da Biblioteca Virtual do Pensamento Social (BVPS), e qualitativos, reunidos a partir de entrevistas feitas com doze pesquisadores seniores da área, originalmente publicada no dossiê "Pensamento social brasileiro", organizado pelo autor em parceria com Lilia Schwarcz, em 2011. A conclusão da análise é interessante: a procura por estabelecer um "programa forte", inspirado criticamente em Jeffrey Alexander, para a área requereria "enfrentar o desafio [...] de desfazer-nos de princípios formais previamente definidos em termos de 'textos' ou 'contextos' para

${ }^{4}$ Sobre o pensamento de Elide Rugai Bastos, além do texto já citado de Brasil Jr., ver Maia (2015) e o comentário-depoimento do próprio Botelho (2018). 
que as múltiplas conexões de sentido entre ideias, intelectuais e sociedades possam, enfim, se tornar um problema efetivo de pesquisa" (Botelho, 2019, p. 267 - grifo do original)

Pelo que foi exposto antes, evidenciam-se as marcas distintivas do trabalho de Botelho: a tomada do pensamento social brasileiro como objeto e ponto de partida para as pesquisas sociológicas em diálogo com a sua tentativa de desprovincianização. Daí a hipótese de que a chave da proposta do autor reside na sua ênfase no "entre", cuja orientação cognitiva requer a relativização de oposições corriqueiras no trabalho intelectual, como externo/interno, ciência/política, passado/presente, clássico/contemporâneo, qualitativo/quantitativo, texto/contexto, teórico/empírico, estrutura/história, entre outras ${ }^{5}$. Nela também parece haver algo que poderíamos chamar de "consciência trágica weberiana" do fazer científico, na medida em que este é sempre trabalho parcial - característica que não deve ser tomada em sentido quietista, antes o contrário. Afinal de contas, o livro é um convite à reflexão sobre a sociedade brasileira, cujo "retorno", como observou Hoelz, pode ser entendido para além da proposta metodológica que procura investigar os modos pelos quais as instituições políticas se situam e interagem com a sociedade a que dizem respeito. Isso porque ela também parece se referir ao fato de que os tempos atuais sugerem uma espécie de retorno do recalcado (Hoelz, 2019), tema central das "interpretações do Brasil" reexaminadas. Mais uma vez, ciência e política em questão.

Pelas razões apontadas, sem perder de vista as singularidades dos trabalhos coligidos, não é ocioso salientar que a operação intelectual que Ihe confere unidade coloca o autor na trilha seguida por alguns dos mais importantes cientistas sociais brasileiros, entre os quais pode-se destacar Lilia Schwarcz (2019), André Singer (2018) e Leonardo Avritzer (2019),

${ }^{5}$ Este ponto ajuda a compreender a aproximação feita por Botelho em relação ao pensamento do crítico literário Silviano Santiago, autor do clássico ensaio "O entre-lugar do discurso latino-americano" (Santiago, 2019) e de uma enriquecedora noção de "cosmopolitismo", retomada pelo sociólogo. Sendo impossível sequer esboçar as linhas de contato, remeto o leitor ao posfácio da edição mais recente de Uma literatura nos trópicos, de autoria de Botelho (2019). 
todos autores que procuram nos clássicos locais algumas das chaves para (re)pensar a sociedade brasileira contemporânea. Na obra síntese de Botelho, passado, presente e futuro, assim como o nacional e o internacional, não são dissociados nem cognitiva, nem politicamente. Nesse espírito, o livro é, também, um programa, remetendo para além de si mesmo. Um belo programa.

Leonardo Octavio Belinelli de Brito é Doutor em Ciência Política pela Universidade de São Paulo (USP) e pós-doutorando no Departamento de Ciência Política da USP.

$\bowtie$ belinelli.leonardo@gmail.com

\section{Referências}

1. ARANTES, Paulo. Providências de um crítico literário na periferia do capitalismo. In: ARANTES, Otília B. F.; ARANTES, Paulo. Sentido da formação. Rio de Janeiro: Paz e Terra, 1997. p.11-66

2. AVRITZER, Leonardo. O pêndulo da democracia. São Paulo: Todavia, 2019.

3. BASTOS, Elide R.; MORAES, João Q. de. O pensamento de Oliveira Vianna. Campinas: Unicamp, 1993.

4. BOTELHO, André. O retorno da sociedade. Petrópolis: Vozes, 2019.

5. BOTELHO, André. Sinal dos tempos: anacronismo e atualidade de Uma literatura nos trópicos. In: SANTIAGO, Silviano. Uma literatura nos trópicos (edição ampliada). Recife: CEPE, 2019. p.361-379.

6. BOTELHO, André. Elide Rugai Bastos: a coragem da sociologia. Blog da Biblioteca Virtual do Pensamento Social (BVPS), 9 mar 2018. Disponível em: https://blogbvps.wordpress.com/2018/03/09/elide-rugai-bastos-a-coragem-dasociologia-por-andre-botelho-ufrj/

7. BOTELHO, André; SCHWARCZ, Lilia. Cidadania, projeto em construção: minorias, justiça e direitos. São Paulo: Claro Enigma, 2012.

8. BRANDÃO, Gildo M. Linhagens do pensamento político brasileiro. São Paulo: Hucitec, 2007.

9. BRASIL JR., Antônio. As ideias como forças sociais: sobre uma agenda de pesquisa. Sociologia \& Antropologia, v. 5, n. 2, p. 553-574, 2015. 
10. CANDIDO, Antônio. Formação da literatura brasileira. Rio de Janeiro: Ouro sobre Azul, 2014.

11. FAORO, Raymundo. Os donos do poder. São Paulo: Globo, 2008.

12. FURTADO, Celso. Formação econômica do Brasil. São Paulo: Companhia das Letras, 2007.

13. HOELZ, Maurício. O método bem temperado. In: BOTELHO, André. O retorno da sociedade. Petrópolis: Vozes, 2019. p. 291-297

14. HOLANDA, Sérgio Buarque. Raízes do Brasil. São Paulo: Companhia das Letras, 2009.

15. MAIA, João Marcelo. Os sentidos da tradição: um estudo de caso no pensamento social brasileiro. Sociologia \& Antropologia, v. 5, n. 2, p. 535-551, 2015.

16. MICELI, Sérgio. Intelectuais e classe dirigente no Brasil (1920-1945). In: MICELI, Sergio. Intelectuais à brasileira. São Paulo: Companhia das Letras, 2001. p. 69-291.

17. SANTIAGO, Silviano. Uma literatura nos trópicos (edição ampliada). Recife: CEPE, 2019. p.361-379.

18. SCHWARCZ, Lilia. Sobre o autoritarismo brasileiro. São Paulo: Companhia das Letras, 2019.

19. SCHWARZ, Roberto. Sobre a "formação" da literatura brasileira. In: SCHWARCZ, Roberto. Sequências brasileiras. São Paulo: Companhia das Letras, 1999. p. 17-23.

20. SINGER, André. O lulismo em crise: um quebra-cabeça do período Dilma (2011-2016). São Paulo: Companhia das Letras, 2018.

21. SKOCPOL, Theda. Bringing the State back in: strategies of analysis in current research. In: EVANS, Peter; RUESCHEMEYER, Dietrich; SKOCPOL, Theda. Bringing the State Back In. New York and Cambridge: Cambridge University Press, 1985. p.3-37.

22. WEBER, Max. Ciência e política: duas vocações. São Paulo: Cultrix, s/d.

Recebido:15 dez. 2019.

Aceito: 12 fev. 2020. 
